\title{
Papilomavírus humano e saúde pública: prevenção ao carcinoma de cérvice uterina
}

\author{
Human papillomavirus and public health: \\ cervical cancer prevention
}

\author{
Angela Adamski da Silva Reis ${ }^{1}$ \\ Caroline Dias M onteiro ${ }^{1}$ \\ Leonardo Barcelos dePaula² \\ Rodrigo da SilvaSantos ${ }^{3}$ \\ VeraAparecida Saddi ${ }^{4}$ \\ Aparecido Divino da $\mathrm{Cruz}^{5}$
}

'D epartamento de Biologia, Pontifícia Universidade Católica de Goiás. 1ậ Av. 1440, Área IV, Bloco L, Setor Universitário.

74605-010 Goiânia GO. angeladamski@gmail.com

${ }^{2}$ Centro Regional de Hemoterapia, Hemocentro deRibeirão Preto,

Universidade de São Paulo.

${ }^{3}$ Programa de Pós-

Graduação em Biologia

Celular e M olecular ,

Instituto deCiências

Biológicas, Universidade

Federal deGoiás.

${ }^{4}$ Pró-Reitoria de Pós-

Graduação ePesquisa,

Pontifícia Universidade

Católica de Goiás.

${ }^{5} \mathrm{~N}$ úcleo de Pesquisas

Replicon, Departamento de

Biologia, Pontifícia

Universidade Católica de

Goiás.
Abstract The present study aimed to evaluate the applicability of an educational booklet that contained information for the general population about promotion and prevention of infections and neoplasic process caused by the human papillomavirus (HPV). The study was arranged in two phases. First, the booklet was given to 200 volunteers in the city of Goiânia, Goiás State. The applicability of the booklet was evaluated without the necessity of proving former knowledge. In the second phase, a detailed analysis of the data was made and the booklet revealed applicable. Then, the educational material was published and 2000 copies were distributed in a social event held by the Pontifícia U niversidade Católica de Góias in thecity of Goiânia. In the event, the booklet raised theinterest of the general public and gavethe volunteers a chance to participate in a study that investigated the presence of the HPV in the genital microbiote. The booklet proved to be applicable and reached its objective to inform and pre vent. However, it's necessary to promote and improvecampaigns to the population about the H PV and its relations with the neoplasic process. Key words HPV, Health education and prevention
Resumo 0 objetivo do presenteestudo foi avaliar a aplicabilidade de uma cartilha educativa, que abordou informaç̃oes de interesse da população para a promoção e prevenção de infecções e neoplasias ocasionadas pelo papilomavírus humano (H PV). $\mathrm{O}$ estudo foi realizado em duas etapas. $\mathrm{Na}$ primeira, a cartilha educativa foi aplicada a duzentos voluntários, na cidade de Goiânia (GO), de ambos os sexos, com nível de escolaridade variando do ensino médio ao superior. A aplicabilidade da cartilha foi avaliada sem a necessidade de conhecimento prévio dos participantes sobre o H PV. Os participantes responderam a um questionário para a avaliação da cartilha. N a segunda etapa, foi feita uma análise detalhada dos dados, ea cartilha mostrou-se aplicável. Posteriormente, o material didático foi publicado e 2.000 exemplares foram distribuídos gratuitamente em um evento de ação social realizado pela Pontifícia U niversidade Católica de Goiás, na cidade de Goiânia. N o evento, a cartilha despertou o interesse dos participantes por informações adicionais e propiciou aos voluntários a oportunidade de participar de um estudo para a investi gação da presença de H PV como microbiota genital. A cartilha demonstrou-se aplicável e atingiu o seu objetivo de informação e prevenção. É necessário promover campanhas deconscientização da população sobre o H PV e sua relação com as neoplasias malignas.

Palavras-chave HPV, Educação em saúde e prevenção 
Introdução

A infecção pelo papilomavírus humano (H PV) é frequentemente comum em adultos jovens de ambos os sexos, com prevalência estimada entre 20 e $46 \%$. A disseminação do HPV tende a ser universal entre os indivíduos sexualmenteativos, sendo o homem um importante fator propagador desse vírus entre as mulheres ${ }^{1-4}$. 0 avanço contínuo das técnicas de detecção molecular tem possibilitado a identificação do genoma viral em associação com diversos tecidos, incluindo as células neoplásicas malignas ${ }^{2,4,5}$.

Dos mais de cem tipos virais molecularmente genotipados, cerca de quarenta tipos têm sido encontrados em infecções na mucosa anogenital, e atualmente éa infecção sexualmente transmissível mais frequente ${ }^{6-9}$. Esses tipos virais são considerados carcinogênicos para o epitélio da cérviceuterina e essa associação ébem estabelecida ${ }^{1,2}$. O DNA dos HPV de alto risco é detectado na maioria (92,9\% a 99,7\%) dos espécimes de câncer cervical invasivo $0^{1,2,6-9}$. Q uanto aos fatores de risco relacionados à infecção por H PV, o número de parceiros sexuais demonstra ser o mais importante 9 . No entanto, outros fatores são considerados para o câncer da cérvice uterino: alta paridade, uso prolongado de contraceptivos orais e tabagismo ${ }^{5}$. Dessa forma, é necessário esclarecer a população sobre as formas de transmissão, diagnóstico, tratamento e formas de prevenção das infecções ocasionadas pelo HPV.

A compreensão da patogênese viral pela população é de grande importância para dinamizar as prevenções primárias e secundárias, gerando um novo enfoquena área da educação em saúde com ênfase no cuidado da saúde das populações humanas. Assim, as cartilhas educacionais aparecem como uma ferramenta eficaz por levar conhecimento consolidado de forma clara e compreensível ao público-alvo ${ }^{10,11}$, gerando transformações conceituais na compreensão da história natural da doença.

Sob a égide "saúde para todos", do M inistério da Saúde/Sistema Ú nico de Saúde, a educação em saúde deve comprometer-se a assistir à população geral ${ }^{12}$. E o interesse na promoção e prevenção da saúde tem como agenda central a problemática das doenças sexualmente transmissíveis (DST). Dessa forma, as infecções causadas por H PV constituem um problema de saúde pública no Brasil e em diversos países. A educação em saúde visa relacionar a qualidade o compromisso com a vida e não, simplesmente, com a ausência de enfermidades ${ }^{10,13}$. Para modificar o eixo do binômio saúde/doença para saúde, é fundamental estimular atitudes enovos procedimentosfrente aos problemas da doença, de modo que a saúde seja encarada como responsabilidade de todos e não somente atribuição governamental.

0 objetivo do presente estudo foi avaliar a aplicabilidade de uma cartilha educativa, que abordou informações de interesse da população para a promoção e preven ção de infecções eneoplasias ocasionadas pelo H PV, com o intuito de gerar mudanças da percepção individual do risco relativo da DST por HPV.

\section{M etodologia}

O material didático utilizado para informar a população geralmente é um instrumento de leitura ou de elementos ilustrativos que chamem a atenção do leitor para o tema abordado. Assim, foi elaborada uma cartilha educativa intitulada "H PV e sua relação com o câncer", contendo desenhos ilustrativos e uma linguagem de fácil entendimento, com informações gerais sobre 0 HPV (Figura 1), incluindo modos de transmissão viral, dados da patologia, diagnóstico e formas de prevenção.

De forma sucinta, as informações sobre o HPV relataram os tipos virais e as regiões anatômicas infectadas pelo vírus. A cartilha introduziu, ainda, noções sobre os tipos virais e a capacidade destes em transformar e imortalizar as células, agindo como um fator de iniciação do processo carcinogênico.

A transmissão sexual é considerada como a principal forma de transmissão do vírus ${ }^{2-4,14}$, incluindo o sexo anal e oral, possuindo relação direta com o número de parceiros sexuais. N esse contexto, além de enfatizá-la como principal forma de transmissão, foram descritas outras como fômites ea contaminação vertical (Figura 2). Esta última merece destaque, pois os papilomas laríngeos e respiratórios recorrentes, de início juvenil, estão associados à infecção por H PV e são transmitidos pela mãe com infecção anogenital ativa ou latente ao recém nascido durante o parto ${ }^{4,15-17}$.

A cartilha também informa aos leitores sobre a necessidade de buscar auxílio do serviço médico para o diagnóstico de infecção pelo H PV nas regiões anogenital e da cabeça e pescoço, quando na presença dos sintomas ou suspeita deinfecção ou presença deneoplasia. No aspecto da prevenção, foi enfatizado o fator de risco da transmissão anogenital, com o objetivo de elucidar aos leitores sobre o HPV ser considerado o 
agente causal do carcinoma da cérvice uterina (Figura 2) e a importância para a mulher da realização do exame preventivo Papanicolaou pe- riodicamente. Além disso, a cartilha estimula o uso de preservativos nas relações sexuais e a redução no número de parceiros.

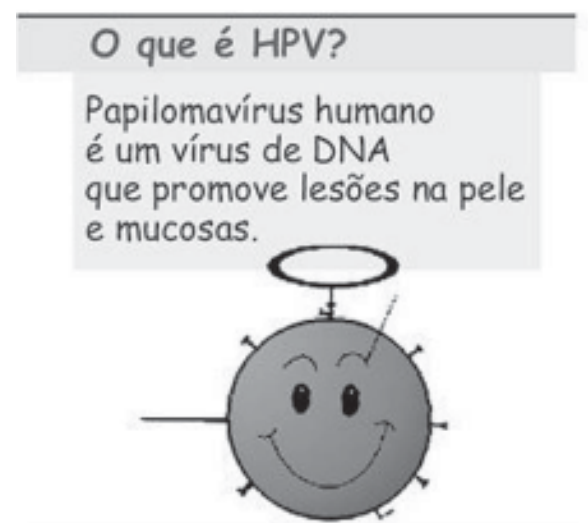

O HPV pode causar câncer ou doença infecciosa que é conhecida como crista de galo, condiloma acuminado ou verruga genital.
São conhecidos mais de 100 tipos virais, 20 dos quais podem infectar o trato genital.

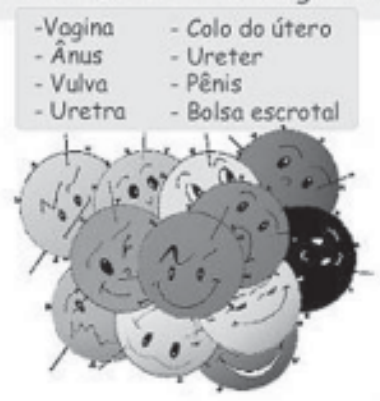

O HPV pode infectar e causar câncer na região da cabeça e pescoço.

- Língua

- Cavidade Oral (boca)

- Lábios

- Orofaringe

- Laringe (garganta)

Figura 1. Cartilha: HPV e sua relação com o câncer, páginas iniciais com informações gerais sobre o Papilomavírus Humano (HPV), os tipos virais e as regiões de infecção.

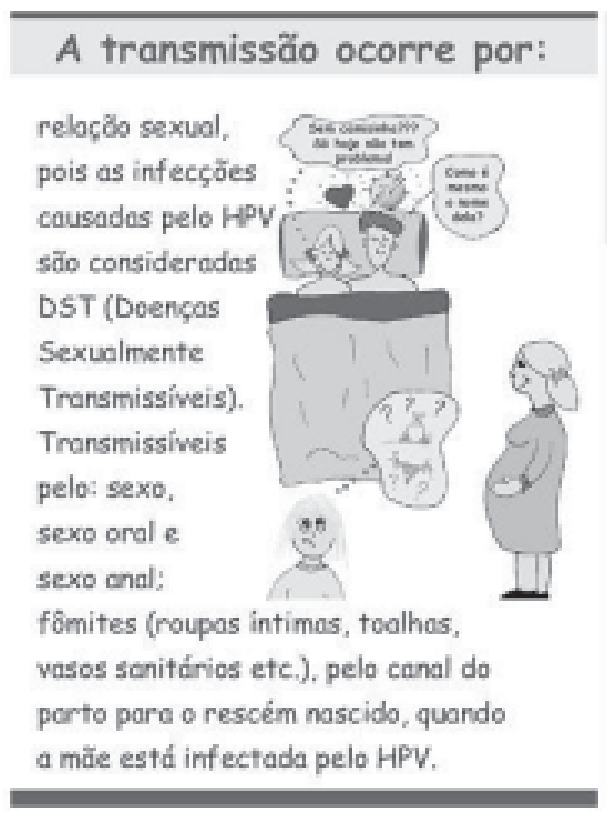

Os véries tipes de HPV podem causor infecçōes que estão relacionadas com o câncer de colo uterino, vagina. vulva, pênis e ânus, como tanbém podem af etar a regiōo da cabeça e pescoço.
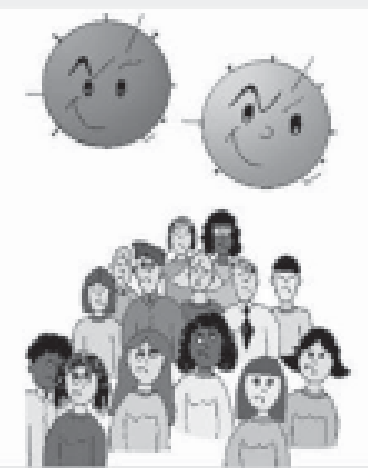

Muitos pesquisadores concluiram que o câncer de colo uterino é causodo pelo HPV em mais de $90 \%$ dos casos.

Figura 2. Parte integrante da cartilha H PV e sua relação com o câncer abordando as formas de transmissão, regiões anatômicas acometidas pelo vírus e associação do Papilomavírus H umano (HPV) com câncer de colo uterino. 
0 estudo foi dividido em duas etapas: a primeira, a avaliação da aplicabilidade da cartilha como instrumento informativo e preventivo, ea outra, com a publicação da cartilha e mediante os resultados satisfatórios, a comprovação da sua aplicabilidade.

$\mathrm{Na}$ primeira etapa, a cartilha educativa intitulada "H PV e sua relação com o câncer" foi aplicada a duzentos voluntários quetrabal havam em diversas categorias de um órgão público estadual na cidade de Goiânia (GO), de ambos os sexos, com nível deescolaridade variando do ensino médio ao superior. A aplicabilidade da cartilha foi avaliada sem a necessidade de conhecimento prévio dos participantes sobre o H PV. Os voluntários assinaram o termo de consentimento e responderam a um questionário após a leitura da cartilha.

0 questionário era composto por doze questões demúltipla escolha, queavaliaram o al cance da cartilha como instrumento de informação e prevenção (Figura 3). As questões eram de caráter educativo, abordando o conhecimento sobre o vírus, as formas de transmissão, as regiões afetadas pela infecção, o risco do processo neoplásico na cérvice uterina, o diagnóstico laboratorial, a prevenção, as expectati vas da cartilha quanto instrumento informativo e o interesse em informações adicionais sobre o H PV.

Após a análise detalhada dos questionários, a segunda etapa foi realizada, sendo publicados 2.000 exemplares edistribuídos gratuitamenteem um evento de ação social, realizado pela Pontifícia Universidade Católica de Goiás, na cidade de Goiânia (GO), de periodicidade anual - a 3a Semana da Cidadania, com público-alvo de 45.000 pessoas. No evento, a cartilha foi distribuída para os visitantes no Espaço Saúde da Mulher, que contou com a participação dos departamentos de Biologia, Biomedicina, Enfermagem e M edicina da UCG. N esse espaço, as mulheres que leram a cartilha e que manifestaram interesse em
1) Vocêjá conhecia o Papilomavírus humano
(HPV)?
$\begin{array}{ll}\text { ( ) sim } \quad(\quad) \text { não }\end{array}$

2) O HPV é considerado uma Doença Sexualmente Transmissível (DST)?

( ) sim ( ) não

3) Tanto o homem quanto a mulher podem transmitir o vírus do HPV?

( ) sim ( ) não

4) Existe o risco da mãe com infecção pelo H PV transmitir o vírus pelo canal do parto ao recém nascido?

( ) sim ( ) não

5) O HPV pode infectar a região genital ea região da cabeça e pescoço, como: boca, laringe, láviose cavidade oral?

( ) sim ( ) não

6) O HPV é considerado como agente causal em $20 \%$ dos casos de câncer de colo uterino?

( ) sim ( ) não
7) Os vários tipos virais são detectados por técnicas altamente específicas e sensíveis como forma de diagnóstico?

( ) sim ( ) não

8) A prevenção, como o Papanicoloau, éa melhor arma contra a infecção e o câncer de colo uterino? ( ) sim ( ) não

9) Esta cartilha informativa aten deu suas expectativas em relação ao conhecimento e esclarecimento sobreo vírus HPV?

( ) sim ( ) não

10) Você acha importante a publicação desta cartilha para a população?

( ) sim ( ) não

11) Vocêgostou da cartilha "HPV e sua relação com o câncer"?

( ) sim ( ) não

6) Você possui interesse em mais informações sobre o HPV?

( ) sim ( ) não

Figura 3. Questionário aplicado nos 200 voluntários para avaliar a aplicabilidade da cartilha HPV e sua relação com o câncer. 
obter informações adicionais foram atendidas, e aquelas queaceitaram participar voluntariamente deum estudo para a investigação da presença de HPV na microbiota genital foram cadastradas e avaliadas para a presença do genoma viral pela reação em cadeia da polimerase (PCR).

\section{Resultados}

Na primeira etapa, a análise dos questionários permitiu avaliar a cartilha como instrumento de informação e prevenção. A faixa etária foi a de 15 a 55 anos de idade, em ambos os sexos, sendo a média de idade de 25 anos. A distribuição percentual por sexo foi de $40,5 \%$ e $59,5 \%$ para os sexos masculino e feminino, respectivamente.

Dos duzentos questionários respondidos, $64,5 \%$ dos leitores não apresentaram conhecimento sobre o HPV e sua relação com o câncer. Para as questões relacionadas à transmissão, às regiões deinfecção, ao diagnóstico eà prevenção, a análise dos dados demonstrou que $90 \%$ do grupo amostral compreendeu o conteúdo abordado pelo instrumento informativo. Para a questão sobre o HPV ser considerado o agente etiológico do câncer da cérvice uterina, verificou-se que somente $74 \%$ dos participantes assimilaram essa informação. No entanto, a cartilha atendeu as expectativas, pois $98 \%$ dos entrevistados gostaram da apresentação e de suas informações, despertando o interesse dos leitores pelas formas deprevenção.

$\mathrm{N}$ a segunda etapa, a cartilha distribuída gratuitamente despertou o interesse de quinhentas mulheres sobreinformações adicionais e pelo exame de detecção molecular para o H PV; destas, duzentas amostras foram coletadas na forma de lavado da cérvice uterina eencaminhadas ao Núcleo de Pesquisas Replicon da UCG para análise de detecção e genotipagem viral pela técnica molecular PCR. Posteriormente, os resultados foram entregues às participantes da análise molecular, e aquelas queapresentaram resultado positivo para detecção do genoma viral foram assistidas no Departamento de M edicina da UCG.

\section{Discussão}

A cartilha educativa intitulada "HPV e sua relação com o câncer" demonstrou que $64,5 \%$ da população analisada não apresentava conheci- mento prévio sobre o HPV. Assim, fica evidente que são necessárias outras metodologias de prevenção e promoção da saúde, sobretudo na saúde da mulher, devido à infecção por H PV ser uma DST e um fator adicional para progressão do carcinoma da cérvice uterina. A população feminina predominou entreosleitores $(59,5 \%)$. N esse contexto, considerando a falta de informação sobre os fatores de risco para desenvolvimento neoplásico, um contingentefeminino, maior alvo de neoplásicas relacionadas ao HPV, foi informado de seus riscos. Assim, a cartilha apresentou sua aplicabilidade quanto à prevenção de uma das neoplasias mais comuns entre as muIheres no mundo.

As questões do questionário que avaliaram a cartilha quanto a sua aplicabilidade nos aspectos da transmissão viral, das regiões afetadas pela infecção, do diagnóstico e da prevenção revelaram a cartilha como instrumento satisfatório de informação, pois os dados demonstram que a população analisada absorveu significativamente o conteúdo informativo. Desta forma, podemos concluir quea cartilha educativa cumpriu seu papel como instrumento de veiculação edivulgação de conhecimento, pois as questões elaboradas eram específicas e procuraram avaliar se o leitor compreendeu o conteúdo informativo.

Quanto às expectativas do leitor sobre a apresentação e as informações da cartilha educativa, verificou-se que $98 \%$ a aprovaram como material referencial para auxilio na obtenção da informação em saúde, além de motivar e despertar o interesse nos leitores para obter mais informações sobre o tema abordado.

A segunda etapa foi consequência do sucesso da primeira etapa. Embora a quantidade de 2.000 exemplares seja pequena para o referido evento da UCG, a cartilha foi publicada em número satisfatório e veiculada a diversos grupos sociais e culturais, podendo-se afirmar que sua distribuição causou impacto e repercussão positivos efoi eficiente na divulgação das informações básicas de prevenção e promoção da saúde naquela população. A carência em estudos que avaliem materiais didáticos na área de educação em saúde compromete o estímulo para novas perspectivas na criação de contextos informativos. Assim, o presente estudo contribuiu para melhorar os horizontes de possibilidades para a educação em saúdee, sobretudo, contribuiu para dinamizar 0 acesso à informação por parte da população leiga. 


\section{Colaboradores}

AAS Reis, CD M onteiro, LB Paula, RS Santos, VA Saddi eAD Cruz participaram igualmente de todas as etapas da elaboração do artigo.

\section{Referências}

1. Maucort-Boulch D, Franceschi S, Plummer $M, M+$ IARC HPV Prevalence Surveys Study Group. International Correlation between Human Papillomavirus Prevalence and Cervical Cancer Incidence. Cancer Epidemiol Biomarkers Prev 2008; 17(3):717-720.

2. Boccardo E, Villa LL. Vírus e Câncer. In: Ferreira CG, da Rocha JCC, organizadores. Oncologia molecular. São Paulo: Atheneu; 2004. p. 123-132.

3. Teixeira JC, Derchain SFM, Teixeira LC, dos Santos CC, Panetta K, Zeferino LC. Avaliação do parceiro sexual e risco de recidivas em mulheres tratadas por lesões genitais induzidas por Papilomavírus Humano (HPV). Rev Bras Ginecol Obstet 2002; 24(5):315-320.

4. Reis AAS. O papel do papilomavírus humano na carcinogênese dos tumores de pênis: uma abordagem epidemiológica e molecular [dissertação]. Goiânia (GO): Universidade Federal de Goiás; 2005.

5. Villa LL. Aspectos moleculares da oncogênese por papilomavírus. In: Bibbo M, Silva Filho AS, organizadores. Lesões relacionadas à infecção por H PV no trato anogenital. Rio de Janeiro: Revinter; 1998. p. 51-58.

6. Trottier H, Franco EL. The epidemiology of genital human papillomavirus infection. Vaccine 2006; 30(24 Suppl 1):S1-S15.

7. Muñoz N, Bosch FX, de Sanjosé $S$, Herrero R, Castellsangué X, Sah KV, Snijders PJ, M eijer CJ, International Agency for Research on Cancer Multicenter Cervical Cancer Study Group. Epidemiological classification of human papillomavirus types associates with cervical cancer. N Engl J Med 2003; 348:518-527.

8. Christy $M$, Hebner Laimoins, A Laimins. Human papillomaviruses: basic mechanisms of pathogenesis and oncogenicity. Rev Med Virol 2006; 16:83-97.
9. zur Hausen $\mathrm{H}$. Human papillomavirus in the pathogenesis of anogenital cancer. Virol 1991; 184:9-13.

10. Candeias NMF. The concepts of health education and promotion-individual and organizational changes. Rev. Saude Publica 1997; 31(2):209-213.

11. Caetano JA, Pagliuca LM F. Cartilha sobre o autoexame ocular para portadores de HIV/AIDS com tecnologia emancipatória: relato de experiência. Rev Eletr Enf 2006; 8(2):241-249.

12. Paim JS, Almeida Filho N. Saúde coletiva: uma "nova saúde pública ou campo aberto a novos paradigmas? Rev. Saude Publica 1998; 32(4):299-316.

13. Grenn LW. Policies for decentralization and development of health education. Rev. Saude Publica 1998; 22:217-220.

14. Eluf $\mathrm{N}$ eto J. Epidemiologia das lesões relacionadas ao HPV. In: Bibbo M, M oraes Filho A, organizadores. Lesões relacionadas à infecção por H PV no trato anogenital. Rio de Janeiro: Revinter; 1998. p. 9-27.

15. Silva AMTC, da Cruz AD, Silva CC. Borges FR, Curado M P. Genotipagem de Papiloma Vírus Humano em paciente com papilomase laríngea recorrente. Rev Brasil Cancerol 2003; 49(3):167-174.

16. Smith EM, Summersgill KF, Allen J, Hoffman HT, McCulloch T, Turek LP, Haugen TH. Human papiIlomavirus and risk of laryngeal cancer. Ann Otol Rhinol Laryngol 2000; 109:1069-1076.

17. Conejo PR, Puerto MJM, Soto AM, M artinez AM, Sanz M AV. Papilomatosis respiratoria recurrente: una causa de dificultad respiratoria progresiva. Annal Esp Pediat 2001; 55(6):558-560.

Artigo apresentado em 26/10/2007

Aprovado em 27/02/2008

Versão final apresentada em 31/03/2008 